\title{
Article
}

\section{Establishment of an internationally agreed minimum data set for acute telestroke}

Cadilhac, DA, Bagot, KL, Demaerschalk, BM, Hubert, G, Schwamm, L, Watkins, Caroline Leigh, Lightbody, Catherine Elizabeth, Kim, J, Vu, M, Pompeani, N, Switzer, J, Caudill, J, Estrada, J, Viswanathan, A, Hubert, N, Ohannessian, R, Hargroves, D, Roberts, N, Ingall, T, Hess, DC, Ranta, A, Padma, V and Bladin, CF

Available at http://clok.uclan.ac.uk/31013/

Cadilhac, DA, Bagot, KL, Demaerschalk, BM, Hubert, G, Schwamm, L, Watkins, Caroline Leigh ORCID: 0000-0002-9403-3772, Lightbody, Catherine Elizabeth ORCID: 0000-0001-5016-3471, Kim, J, Vu, M et al (2021) Establishment of an internationally agreed minimum data set for acute telestroke. Journal of Telemedicine and Telecare, 27 (9). pp. 582-589. ISSN 1357-633X

It is advisable to refer to the publisher's version if you intend to cite from the work. $10.1177 \% 2 \mathrm{~F} 1357633 \times 19899262$

For more information about UCLan's research in this area go to http://www.uclan.ac.uk/researchgroups/ and search for <name of research Group>.

For information about Research generally at UCLan please go to http://www.uclan.ac.uk/research/

All outputs in CLoK are protected by Intellectual Property Rights law, including Copyright law. Copyright, IPR and Moral Rights for the works on this site are retained by the individual authors and/or other copyright owners. Terms and conditions for use of this material are defined in the policies page. 


\section{Establishment of an internationally agreed minimum data set for acute telestroke}

Cadilhac DA $(\mathrm{PhD})^{1,2}$, Bagot KL $(\mathrm{PhD})^{1,2}$ Demaerschalk BM (MD) ${ }^{3}$, Hubert $\mathrm{G}^{4}$, Schwamm $\mathrm{L}^{5}$, Watkins $\mathrm{CL}^{6}$ Lightbody $\mathrm{CE}^{6}$, Kim J $(\mathrm{PhD})^{1,2}, \mathrm{Vu} \mathrm{M}^{7}$, Pompeani N $(\mathrm{PhD})^{1}$, Switzer J ${ }^{8}$, Caudill $\mathrm{J}^{8}$, Estrada $\mathrm{J}^{5}$, Viswanathan $\mathrm{A}^{5}$, Hubert $\mathrm{N}^{4}$, Ohannessian $\mathrm{R}^{9}$, Hargroves $\mathrm{D}^{10}$, Roberts $\mathrm{N}^{11}$, Ingall $\mathrm{T}^{12}$, Hess DC (MD) ${ }^{8}$, Ranta $\mathrm{A}^{13}$, Padma $\mathrm{V}^{14}$, Bladin $\mathrm{CF}^{1,15,16}$

${ }^{1}$ Public Health Group, Stroke Division, the University of Melbourne, Florey Institute of Neuroscience and Mental Health, Heidelberg, Australia

${ }^{2}$ Stroke and Ageing Research, Department of Medicine, School of Clinical Sciences at Monash Health, Monash University, Victoria, Australia

${ }^{3}$ Department of Neurology and Center for Connected Care, Mayo Clinic College of Medicine and Science, Rochester, Minnesota, USA

${ }^{4}$ TEMPiS telemedical stroke center, Department of Neurology, Munich Municipal Hospital Group, Munich, Germany

${ }^{5}$ Partners Telestroke Program, Department of Neurology, Massachusetts General Hospital, Harvard Medical School, Boston, MA, USA.

${ }^{6}$ Faculty of Health and Wellbeing, University of Central Lancashire, Preston, UK

${ }^{7}$ Clinical Services, Epworth HealthCare, Richmond, Victoria, Australia

${ }^{8}$ Department of Neurology, Medical College of Georgia at Augusta University, Augusta, GA

${ }^{9}$ Laboratoire de Neurosciences Intégratives et Cliniques, Université de Franche-Comté, UBFC, France; Télémédecine 360, TLM360, France10 Stroke Medicine, East Kent University Hospitals, UK

${ }^{10}$ East Kent Hospital University NHS Foundation Trust, UK

${ }^{11}$ East Lancashire Hospitals NHS Trust, UK

${ }^{12}$ Department of Neurology, Mayo Clinic College of Medicine and Science, Phoenix, Arizona, USA

${ }^{13}$ Department of Medicine, University of Otago Wellington, Wellington, New Zealand

${ }^{14}$ Department of Neurology, AIIMS, Delhi, India

${ }^{15}$ Ambulance Victoria, Melbourne, Australia

${ }^{16}$ Eastern Health Clinical School, Melbourne, Australia

Correspondence: dominique.cadilhac@monash.edu 


\section{FILE \#1: DETAILED METHODS}

\section{Phase 1: Identification of potential variables}

The potential pool of variables was identified by searching the academic literature, grey literature, and contacting our colleagues involved in telestroke programs. This aspect was commenced in 2015. A review of the academic and grey literature included keyword combinations of 'telemedicine', 'telestroke', 'telecommunications', 'technology' and 'acute stroke', and 'care', 'processes', 'monitoring', 'evaluation'. Searches were limited to: 1) the English language, and 2) full text available. Websites of telemedicine networks identified through literature or colleagues were also examined. Data collection tools and data dictionaries were sourced directly from established telemedicine networks in Australia (Victorian Stroke Telemedicine program), ${ }^{1,2}$ Germany (TEMPIS), ${ }^{3}$ United States of America (REACH and STROKE DOC) $)^{4,5}$ and the United Kingdom (ASTUTE). ${ }^{6}$

Processes of acute stroke care and patient outcomes relevant to telestroke were reviewed from the identified publications (and their reference lists). Reported summary variables such as quality indicators that might be derived from two or more variables (e.g., door-to-needle time) and associated, specific variables (e.g., patient arrival time, needle time) were extracted. Seeking additional sources ceased when no new variables were identified. The variable options were then summarised into three major themes: Service configuration, Consultations, and Patient information.

Same or similar variables were harmonised i.e. merged and translated into a common language from within and between different data sources ${ }^{7}$. Where applicable, authors KB, NP and DAC reviewed and made a decision to use the simpler English representation of the variable to be described.

\section{Phase 2: Review of variable options via modified Delphi technique}

The review process of the potential variable options was undertaken using a modified Delphi technique. ${ }^{8,9}$ This well-established group communication process provides a method for consensus-building from a group of experts. ${ }^{8,9}$ Our modified Delphi technique involved an expert panel undertaking two rounds of on-line surveys, with iterative teleconferences and document circulation via email to review and discuss interim and final results. Not all members participated in each phase and some joined later as part of an iterative feedback process. The basic principles for choosing the TS-MDS variables was to select those that would be critical to evaluating a telestroke program and be meaningful as a collective set.

\section{Expert Panel}

Consistent with establishing Delphi panels,${ }^{10}$ we set no limit to the panel size. Participation required experience and expertise with acute stroke care within a telemedicine context, including clinical, research and/or management perspective. Using our networks and through our review of the literature, we identified and invited an international panel of 23 experts actively involved in telestroke programs or research from Australia $(n=4)$, New Zealand $(n=1)$, United States of America $(n=8)$, England $(n=4)$, France $(n=1)$, Germany $(n=2)$, and India $(n=3)$. Panel members represented clinicians, researchers or telestroke managers to ensure broad representation. In some instances, Directors of telestroke programs delegated participation to another team member with a relevant interest in this project (e.g., data manager). Each program could have more than one participant, if desired.

\section{Written surveys}

Two surveys were administered online (Survey Monkey®, online survey software) focusing on reviewing each potential variable. At this stage, we did not offer variable response options. We also collected information to describe the characteristics of the experts who responded to these surveys such as role and amount of telestroke experience. 
Participants were asked to consider each variable and determine its importance for retention. Response options were on a 5-point Likert scale: 1 'totally irrelevant', 2 'irrelevant', 3 'indifferent', 4 'relevant', and 5 'totally relevant'. Each item also included an open-ended question with a free-text box. Members of the expert panel were also invited to nominate additional variables that were not included, but that they considered would be of value for a TS-MDS.

Subsequently, the first survey results were collated with the percentage agreement calculated for each item. Cut-off points for degree of concordance determined if the item would be included $(\geq 80 \%)$, excluded $(<50 \%)$ or if further review would be required $(50 \%-79 \%)$ (see also Data management and analysis section). The variables were then reorganised into these categories and were distributed to panel members for a second round of review and feedback.

The second survey included variables that required further review or had achieved poor agreement in the first round, plus participant demographics. Panel members were invited to complete the same relevance scale as presented in the first survey and to review the potentially excluded items and nominate any items that should be retained.

Subsequently, these survey results were collated and combined with the first survey results and distributed to panel members for a final review.

\section{Consensus meetings via teleconference}

In the next review stage, the expert panel met by teleconference to discuss the survey results and identify opportunities for further harmonisation and refinement. Two separate teleconferences were held to discuss the remaining items from round 2 that had received 50$79 \%$ agreement. The separate teleconferences were required due to time zone differences and to encourage more options for participation. The first teleconference was between experts from Australia and America, and the second between participants from Australia, England and Europe.

\section{Phase 3: Finalise variables and propose suggested response options}

Once the final TS-MDS variables had been identified from Phase 2, variable wording and potential response options were identified or developed for the patient-level and organisational level questions, as required. For this latter task, we drew on established data dictionaries from the Australian National Stroke Data Dictionary (NSDD, established 2016; https://strokefoundation.org.au/Australian\%20Stroke\%20Coalition/AusDAT), the Australian Institute of Health and Welfare Metadata Online Registry (METeOR; established 2005), and the American Heart Association's Get With The Guidelines ${ }^{\circledR}$ - Stroke (GWTG; established 2003). ${ }^{11}$ METeOR (https://meteor.aihw.gov.au/content/index.phtml/itemId/181162 ) provides nationally endorsed data definitions and standards, and is used by stroke-specific data collection systems including the Australian Stroke Clinical Registry (AuSCR; established 2009) ${ }^{12}$ and the AuSDaT (established 2016).

The finalised variables and proposed response options were distributed via email to panel members for review and feedback. The results have been compiled as part of this publication and are presented in the Supplemental File - Data Dictionary. 


\section{Supplemental References Detailed Methods}

1. Bladin CF, Moloczij N, Ermel S, Bagot KL, Kilkenny M, Vu M, et al. Victorian Stroke Telemedicine Project: implementation of a new model of translational stroke care for Australia. Intern Med J. 2015;45:951-956

2. Bagot KL, Cadilhac DA, Kim J, Vu M, Savage M, Bolitho L, et al. Transitioning from a single-site pilot project to a state-wide regional telehealth service: the experience from the Victorian Stroke Telemedicine programme. J Telemed Telecare. 2017;23:850-855

3. Audebert HJ, Schultes K, Tietz V, Heuschmann PU, Bogdahn U, Haberl RL, et al. Long-term effects of specialized stroke care with telemedicine support in community hospitals on behalf of the Telemedical Project for Integrative Stroke Care (TEMPiS). Stroke; a journal of cerebral circulation. 2009;40:902-908

4. Meyer BC, Raman R, Hemmen T, Obler R, Zivin JA, Rao R, et al. Efficacy of siteindependent telemedicine in the STRokE DOC trial: a randomised, blinded, prospective study. Lancet Neurol. 2008;7:787-795

5. Hess DC, Wang S, Hamilton W, Lee S, Pardue C, Waller JL, et al. REACH: clinical feasibility of a rural telestroke network. Stroke; a journal of cerebral circulation. 2005;36:2018-2020

6. Gibson J, Fitzgerald J, Gibson A, McAdam J, Lightbody L, McLoughlin A, et al. Using telemedicine for acute stroke assessment. Nursing times. 2013;109:14-16

7. Svensson-Ranallo PA, Adam TJ, Sainfort F. A framework and standardized methodology for developing minimum clinical datasets. AMIA Joint Summits on Translational Science proceedings AMIA Summit on Translational Science. 2011;2011:54-58

8. Ozier W. The Delphi/Modified Delphi technique: a consensus approach to information valuation. . 1998;2016

9. Hsu C-C, Sandford BA. The Delphi technique: making sense of consensus. Prac Assess Eval. 2007;12:1-8

10. Akins RB, Tolson H, Cole BR. Stability of response characteristics of a Delphi panel: application of bootstrap data expansion. BMC medical research methodology. 2005;5:37-49

11. Schwamm LH, Fonarow GC, Reeves MJ, Pan W, Frankel MR, Smith EE, et al. Get With the Guidelines - stroke is associated with sustained improvement in care for patients hospitalized with acute stroke or transient ischemic attack. Circulation. 2009;119:107-115

12. Cadilhac D, Lannin N, Anderson C, Levi C, Faux S, Price C, et al. Protocol and pilot data for establishing the Australian Stroke Clinical Registry (AuSCR). International journal of stroke : official journal of the International Stroke Society. 2010:217-226 


\section{FILE \#2: DATA DICTIONARY}

The following Tables outline each of the variables and recommended variable coding for setting up a database for acute telestroke services. Following these formats will permit the ability to reliably pool data or make comparisons between projects/programs.

\section{Contents}

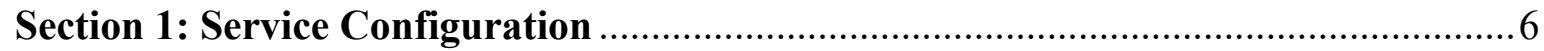

Details about Telestroke Program/Network................................................................ 6

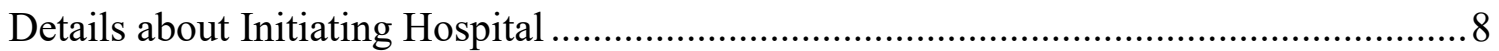

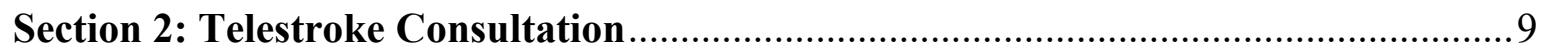

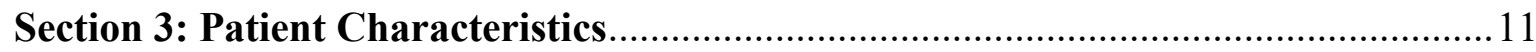

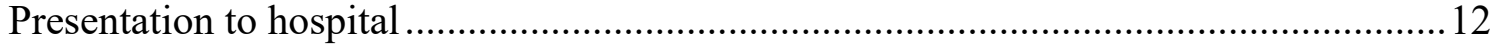

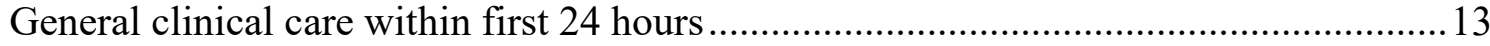

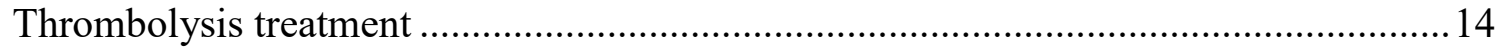

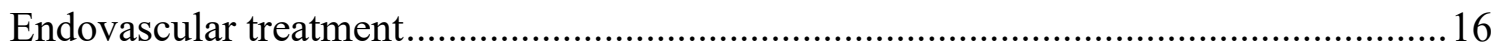

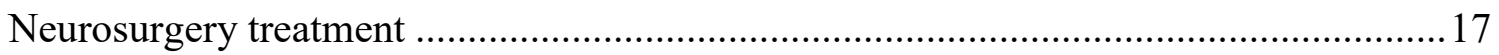

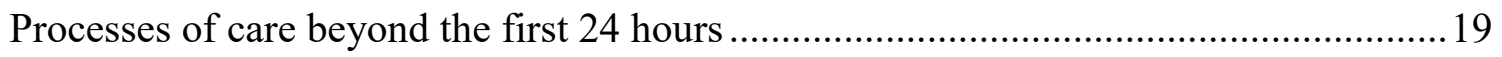

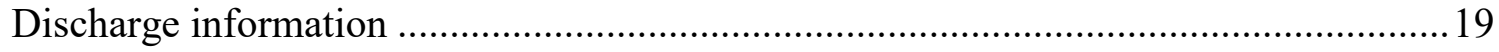

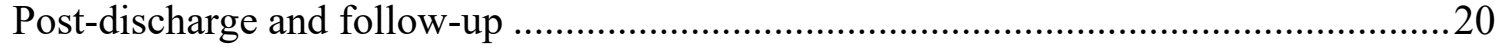

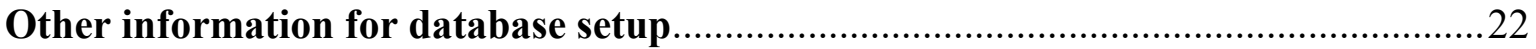

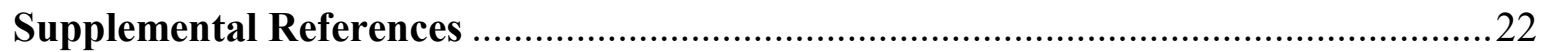




\section{Section 1: Service Configuration}

\section{Details about Telestroke Program/Network}

\section{\begin{tabular}{|c|c}
\hline Variable & Recommended response options and variable coding
\end{tabular} \\ 1. What year did the telestroke network commence? \\ - Year commenced first pilot site / program \\ o YYYY e.g., 2018 (only numeric text) \\ - N/A (no pilot site / program used) \\ - Year commenced established network \\ ○ YYYY e.g., 2018 (only numeric text) \\ - N/A (only currently have a pilot program underway)}

- Any comments about the year your telestroke network commenced (free text box)

2. What type of telestroke network model is being used?
3. Is the telestroke service available within the Mobile Stroke Unit/Ambulance (MSU)? (select one option)

- Hub-and-spoke

(Centralised model where specialists are at a single site, e.g., hospital, organisation i.e., 'hub' providing consultations to clinicians at multiple other sites i.e., 'spokes')

- Distributed

(Decentralised model where specialists are at multiple sites, e.g., hospitals providing consultations to clinicians dispersed across other hospitals)

- Horizontal

(Decentralised model where specialists provide consultations to clinicians within the same hospital network)

- Other

○ (specify other model) (free text)
(Select one option)

1. Yes, telestroke is available within the MSU

2. No, telestroke is not available within the MSU

9. N/A, we do not have an MSU
4. Does the telestroke service provider network profit from providing service?
$($ select those that apply. If selected, code $=1)$

- Our service provider is a for-profit service

- Our service provider is not-for-profit

- Our service provider is public

- Our service provider is private

Free text box

(select those that apply. If selected, code $=1$ )

- Neurologist

○ $\mathrm{NN}$ (write number of neurologists e.g., 05 or 11)

- Stroke physician

○ NN (write number of stroke physicians e.g., 05 or 11)

- Stroke geriatrician 
7. How many spoke hospitals are there, and how many of these actively utilise telestroke consultations? $\circ \quad \mathrm{NN}$ (write number of stroke geriatricians e.g., 05 or 11)

- Advanced nurse practitioner

- NN (write number of adv. nurse pract. e.g., 05 or 11)

- Other

○ (specify other discipline(s)) (free text)

○ $\mathrm{NN}$ (write number for each discipline specified.)

- Number of spoke hospitals

○ NNN (write number of spoke hospitals e.g., 008) (only numeric text)

- Number of hospitals utilising telestroke consultations

- NNN (write number of hospitals utilising telestroke e.g., 005) (only numeric text)

8. What are the days and hours of operation that the telestroke consultations are available?

9. What telestroke consultation employment model is used? (select those that apply. If selected, code $=1$ )

- $24 / 7$

- Outside 8 am to 5 pm Monday to Friday (i.e., after hours, weekends)

- For backfill purposes only (e.g., vacation, public holiday)

- Other

$\circ \quad$ (specify other) (free text)

(select one option)

1. Consultations part of consultants' work plan

2. Consultations in addition to usual work role

- If separate to usual work role, then roster structure

(1) 8 hour shift

(2) 12 hour shift

(3) 24 hour shift

(4) 48 hour shift

(5) Other

(specify other) (free text)
10. Where are telestroke consultants providing consults from?

11. What is the telestroke consultation remuneration model for consultation providers? (select one option)

- Mobile location

- Fixed location

1. Fee per consultation

2. On-call fee + Fee per consultation

3. Fee per session/shift

4. On-call fee + Fee per session/shift

5. Other $\circ \quad$ (specify other) (free text)

12. Are there written agreements between hospitals/services providing telestroke services and hospitals using telestroke services for exchange of patient data (e.g., arrival time at receiving hospital or patient outcome post discharge to be

\section{(select one option)}

1. Yes, there is a written agreement

2. No, there isn't a written agreement 
provided to originating hospital or telestroke network)?

\section{Details about Initiating Hospital}

13. What are the operating days / hours that telestroke consultations are utilised? (select one option)

- $24 / 7$

- outside 8 am to $5 \mathrm{pm}$ Monday to Friday (i.e., after hours, weekends)

- for backfill purposes only (e.g., vacation, public holiday)

- Other $\circ \quad$ (specify other) (free text)
14. Does your hospital have a stroke unit?

15. Does the hospital have stroke specialists on staff? (i.e., excluding those accessed via telestroke).
1. Yes

2. No (select one option only)

1. Yes, hospital has stroke specialist employed business hours only

2. Yes, hospital has stroke specialist employed $24 / 7$

3. No, hospital does not have stroke specialist employed

16. Does hospital drip-and-ship postthrombolysis?

(select one option)

1. Yes

2. No

9. Not applicable (hospital does not provide thrombolysis)

(select one option)

1. Yes

2. No

(select one option)

1. Yes

2. No

19. What is the distance from the tertiary centre / comprehensive stroke centre / treating hospital (e.g., for postthrombolysis care, for ECR or nonECR neurosurgical procedure)?

\section{(select one option)}

1. $0-10 \mathrm{~km}$

2. $10-50 \mathrm{~km}$

3. $50-100 \mathrm{~km}$

4. $100-200 \mathrm{~km}$

5. $>200 \mathrm{~km}$

20. How many beds are in the stroke unit?

NNN (write number of beds in stroke unit e.g., 020) (only numeric text)

21. Is real time video and audio available (select one option) between telestroke using hospital and telestroke consultants?

1. Yes

2. No

22. Is CT imaging available remotely to telestroke consultants?

\section{(select one option)}

1. Yes

2. No

9. Unknown/not documented 


\section{Section 2: Telestroke Consultation}

\begin{tabular}{|c|c|}
\hline Variable & Suggested/Preferred Response Options (Coding) \\
\hline $\begin{array}{l}\text { 23. Was a telestroke consultation } \\
\text { conducted? }\end{array}$ & $\begin{array}{l}\text { (select one option) } \\
\text { 1. Yes } \\
\text { 2. No } \\
\text { 9. Unknown/not documented }\end{array}$ \\
\hline $\begin{array}{l}\text { 24. What was the reason a } \\
\text { telestroke consultation was } \\
\text { requested? (select one answer } \\
\text { option) }\end{array}$ & $\begin{array}{l}\text { (select one answer option) } \\
\text { 1. Hyperacute (thrombolysis; other) } \\
\text { 2. Acute (assessment; case conference; other) } \\
\text { 3. Rehabilitation (assessment/review; therapy; case conference; other). } \\
\text { 8. Other } \\
\quad \text { (specify reason for consult) (free text box) }\end{array}$ \\
\hline $\begin{array}{l}\text { 25. Date and start time of when } \\
\text { the telestroke neurologist was } \\
\text { first contacted by telephone }\end{array}$ & $\begin{array}{l}\text { - Date } \\
\text { O DDMMYYYY (only numeric text) } \\
\text { - Time: } 24 \mathrm{hr} \text { time } \\
\circ \text { hh:mm (e.g., 13:53) (only numeric text) } \\
\circ \text { Unknown/not documented }\end{array}$ \\
\hline $\begin{array}{l}\text { 26. What was the mode of } \\
\text { consultation? }\end{array}$ & $\begin{array}{l}\text { 1. Both phone and video } \\
\text { 2. Phone only } \\
\text { 3. Video only } \\
\text { 8. Other (e.g., electronic mail) } \\
\quad \text { (specify mode of consult) (free text box) }\end{array}$ \\
\hline $\begin{array}{l}\text { 27. Who was present at receiving } \\
\text { hospital during the } \\
\text { consultation? }\end{array}$ & $\begin{array}{l}\text { (select those that apply. If selected, code }=1 \text { ) } \\
\text { - Clinical support staff at receiving hospital present } \\
\text { - Medical registrar } \\
\text { - Stroke specialist nurse } \\
\text { - Emergency department nurse } \\
\text { - Consultant Physician } \\
\text { - Other } \\
\text { O }\end{array}$ \\
\hline $\begin{array}{l}\text { 28. What was the duration of the } \\
\text { video call / consultation? }\end{array}$ & 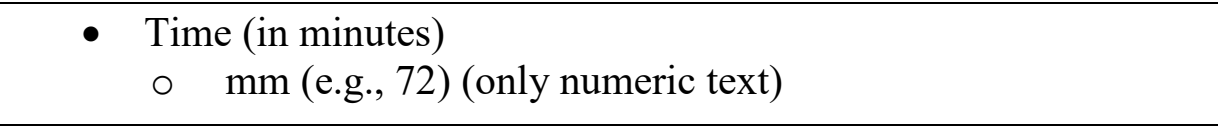 \\
\hline $\begin{array}{l}\text { 29. What were the technical } \\
\text { observations / difficulties } \\
\text { experienced (by remote } \\
\text { consultant)? }\end{array}$ & $\begin{array}{l}\text { (select those that apply. If selected, code }=1 \text { ) } \\
\text { - Phone - audio quality } \\
\text { - VC - unable to login to software } \\
\text { - VC - audio } \\
\text { - VC - vision lag } \\
\text { - VC - vision drop out } \\
\text { - Unable to connect to the cart } \\
\text { - PACS - image quality not suitable } \\
\text { - PACS - unable to log in } \\
\text { - Error message } \\
\text { - Other } \\
\text { - } \quad \text { No problems experienced }\end{array}$ \\
\hline
\end{tabular}


30. Was a review of CT imaging completed by telestroke consultant?

31. If yes, what was the date/time of review?

(select one option)

1. Yes

2. No

9. Unknown/not documented

- Date

- DDMMYYYY (only numeric text)

- Time: $24 \mathrm{hr}$ time

○ hh:mm (e.g., 13:53) (only numeric text)

○ Unknown/not documented

32. What was the preliminary diagnosis by the telestroke consultant?

(select one answer option)

1. Ischaemic

2. Intracerebral Haemorrhage

3. Transient ischaemic attack

4. Not Stroke

5. Undetermined

(select one option)

33. Did telestroke consultant decide/recommend to thrombolyse?

1. Yes

2. No

9. Unknown/not documented

34. Was the thrombolysis recommendation followed by the hospital?

(select one option)

1. Yes

2. No

9. Unknown/not documented

35. Did the telestroke consultant decide / recommend (evaluation of) endovascular clot retrieval?

(select one option)

1. Yes

2. No

9. Unknown/not documented

(select one option)

36. Was the endovascular recommendation followed by the receiving hospital?

37. Did telestroke consultant decide/recommend neurosurgical treatment?

38. Was the other neurosurgical treatment followed by the hospital?

1. Yes

2. No

9. Unknown/not documented

(select one option)

1. Yes

2. No

9. Unknown/not documented (select one option)

1. Yes

2. No

9. Unknown/not documented

39. National Institute of Health Stroke Scale (i.e., measure of

- Score stroke severity) score calculated by telestroke consultant or local clinicians at time of presentation

$\circ \quad \mathrm{NN}$ (e.g., 0-42, 99 not documented) (only numeric text) 


\section{Section 3: Patient Characteristics}

\section{Socioeconomic demographics}

\begin{tabular}{l|l}
\hline \multicolumn{1}{|c|}{ Variable } & \multicolumn{1}{|c}{ Suggested/Preferred Response Options (Coding) } \\
\hline 40. Gender & (select one option) \\
& 1. Male \\
& 2. Female \\
& 3. Intersex or indeterminate \\
& 9. Not stated/inadequately described \\
\hline
\end{tabular}

41. Date of Birth and age (at presentation to hospital)

- Date

- DDMMYYYY (only numeric text)

- Age calculated automatically from DOB and date of admission

42. Did the patient have any history of known risk factors prior to admission? (select those that apply. If selected, code $=1$ )
( select those that apply. If selected, code $=1$ )

- Diabetes

- Atrial Fibrillation

- Coronary Artery Disease

- Hypertension

- Serious illness that influences prognosis or management of stroke

- Other

- State Other:

- Unknown/not documented

- Post code/ zip code (free text - 10 characters)

- Homeless

○ Unknown/not documented
43. Post code/ Zip code

44. Living arrangements prior to admission? (select one option)

1. Home (alone)

2. Home (with others)

3. Supported accommodations e.g., nursing home, hostel

4. Other

o

9. Unknown/not documented

(select one option)

1. Yes

2. No

9. Unknown/not documented

46. Arrival by ambulance/EMS/MSU?

(select one option)

1. Yes

2. No

9. Unknown/not documented

If yes, record mode of transport used:

- Road Ambulance/Emergency Medical Service - Standard - Mobile Stroke Unit

- Air Ambulance/Emergency Medical Service o Plane ○ Helicopter 


\section{Presentation to hospital}

47. Functional status prior to stroke? (mRS).

(select one option)

0 . No symptoms.

1. No significant disability. Able to carry out all usual activities, despite some symptoms.

2. Slight disability. Able to look after own affairs without assistance, but unable to carry out all previous activities.

3. Moderate disability. Requires some help, but able to walk unassisted.

4. Moderately severe disability. Unable to attend to own bodily needs without assistance, and unable to walk unassisted.

5. Severe disability. Requires constant nursing care and attention, bedridden, incontinent.

9. Unknown/not documented.

48. Previous history of stroke.

(select one option)

1. Yes

2. No

9. Unknown/not documented

49. NIHSS at baseline

- Score

NN (e.g., 0-42, 99 not documented) (only numeric text)

50. Did the stroke occur while the patient was in (select one option) hospital?

1. Yes

2. No

9. Unknown/not documented

51. Was the patient transferred from another (select one option) hospital?

1. Yes

2. No

9. Unknown/not dcoumented

If yes, select reason(s) for transfer (if selected, code=1)?

Reasons:

- Need for intravenous tPA;

- Need for stroke unit care;

- Need for rehabilitation;

- Need for BRAIN IMAGING only;

- Need for ICU;

- Need for specialist medical assessments;

- Need for surgical interventions;

- Need for diagnostic tests;

- Need for Coordinated Care by a Stroke Service;

- Unknown;

- Other:

○ _ (specify other) (free text box) 
52. Stroke symptom onset date/time

53. Discovery of patient with stroke symptoms date/time
- Date

- DDMMYYYY (only numeric text)

- Time: $24 \mathrm{hr}$ time

○ hh:mm (e.g., 13:53) (only numeric text)

- Time accuracy

- $\quad \mathrm{KWN}=$ Known time of onset

$\circ \quad \mathrm{UNC}=$ If uncertain time of onset, then time last seen well

$\circ \quad$ WAK = If wake up stroke, then time last seen well

$\circ \quad \mathrm{TU}=$ Time unknown

- Date

- DDMMYYYY (only numeric text)

- Time: $24 \mathrm{hr}$ time

○ hh:mm (e.g., 13:53) (only numeric text)

○ Unknown/not documented

- Date

○ DDMMYYYY (only numeric text)

- Time: $24 \mathrm{hr}$ time

○ hh:mm (e.g., 13:53) (only numeric text)

○ Unknown/not documented

55. Did the patient have a brain scan after this stroke?

1. Yes

2. No

9. Unknown/not documented

(select those that apply. If selected, code $=1$ )

- $\mathrm{CT}$

- MRI

- Date

- DDMMYYYY (only numeric text)

- Time: $24 \mathrm{hr}$ time

○ hh:mm (e.g., 13:53) (only numeric text)

○ Unknown/not documented

58. Neuroexamination date/time

- Date

○ DDMMYYYY (only numeric text)

- Time: $24 \mathrm{hr}$ time

○ hh:mm (e.g., 13:53) (only numeric text)

○ Unknown/not documented

59. Final ED diagnosis (select only one answer)

(select one answer option)

1. Ischaemic

2. Intracerebral Haemorrhage

3. Transient ischaemic attack

4. Not Stroke

5. Undetermined 


\begin{tabular}{l|l}
\hline 60. Definite new diagnosis of acute stroke & $\begin{array}{l}\text { (select one option) } \\
\text { 1. Yes } \\
\text { 2. No } \\
\text { 9. Unknown/not documented }\end{array}$ \\
\hline 61. Decision to proceed to neurosurgery date/time & $\quad$ Date \\
& $\quad$ DDMMYYYY (only numeric text) \\
& Time: $24 \mathrm{hr}$ time \\
& $\quad$ hh:mm (e.g., 13:53) (only numeric text)
\end{tabular}

\section{Thrombolysis treatment}

62. Date and time of decision to thrombolyse

- Date

○ DDMMYYYY (only numeric text)

- Time: $24 \mathrm{hr}$ time

○ hh:mm (e.g., 13:53) (only numeric text)

○ Unknown/not documented

63. Reason no thrombolysis given despite being recommended for an ischaemic stroke occurring within 4.5 hours of onset.

(Select those that apply. If selected, code $=1$ )

- Rapidly improving symptoms

- Symptoms $>4.5 \mathrm{hrs}$

- Comorbidities

- Current use of oral anticoagulants

- Advanced age

- Pre-stroke $\mathrm{mRS}>2$

- Infarct core $>1 / 3 \mathrm{MCA}$ territory qualitatively

- Previous stroke within the last 3 months

- Uncontrolled hypertension

- CT contraindicated

- Use of glycoprotein IIb-IIIa Inhibitors within past $72 \mathrm{hrs}$

- Exposure to thrombolytic agent within the previous $72 \mathrm{hrs}$

- Patient/family refused

- Pregnant woman (clinically evident)

- Recent history or clinical presentation of ICH, $\mathrm{SAH}, \mathrm{AV}$ malformation, aneurysm or cerebral neoplasm

- Low NIHSS

- Use of heparin in the past $48 \mathrm{hrs}$

- A condition posing potential hazard to participant if tPA initiated

- Clinically significant hypoglycaemia

- Hereditary or acquired haemorrhagic diathesis

- Gastrointestinal or urinary bleeding with the past 21 days

- Major Surgery

- Other

$\circ \quad$ (specify other reason) (free text box)

64. How was the decision to thrombolyse made?

(select one option) (select only one answer)

1. Telephone with imaging

2. Videolink 


\begin{tabular}{|c|c|}
\hline & $\begin{array}{l}\text { 3. Other } \\
\bigcirc \\
\text { 9. Unknown/not documented }\end{array}$ \\
\hline 65. Did patient consent for thrombolysis treatment? & $\begin{array}{l}\text { (select one option) } \\
\text { 1. Yes } \\
\text { 2. No } \\
\text { 9. Unknown/not documented }\end{array}$ \\
\hline $\begin{array}{l}\text { 66. Date and time of patient consent for thrombolysis } \\
\text { treatment }\end{array}$ & $\begin{array}{l}\text { - Date } \\
\text { ○ DDMMYYYY (only numeric text) } \\
\text { - Time: } 24 \text { hr time } \\
\circ \text { hh:mm (e.g., 13:53) (only numeric text) } \\
\circ \text { Unknown/not documented }\end{array}$ \\
\hline $\begin{array}{l}\text { 67. What was the date and time thrombolysis } \\
\text { commenced? }\end{array}$ & $\begin{array}{l}\text { - Date } \\
\text { ○ DDMMYYYY (only numeric text) } \\
\text { - Time: } 24 \mathrm{hr} \text { time } \\
\circ \quad \text { hh:mm (e.g., 13:53) (only numeric text) } \\
\circ \quad \text { Unknown/not documented }\end{array}$ \\
\hline $\begin{array}{l}\text { 68. Was there a serious adverse event related to } \\
\text { thrombolysis? }\end{array}$ & $\begin{array}{l}\text { (select one option) } \\
\text { 1. Yes } \\
\text { 2. No } \\
\text { 9. Unknown/not documented }\end{array}$ \\
\hline $\begin{array}{l}\text { 69. Types of complications/adverse event of } \\
\text { thrombolysis }\end{array}$ & $\begin{array}{l}\text { (Select those that apply. If selected, code }=1) \\
\text { - Symptomatic/asymptomatic brain haemorrhage } \\
\text { - Angioedema } \\
\text { - Extra cranial bleed } \\
\text { - Other: } \\
\text { o } \frac{}{\text { box) }} \text { (specify other adverse event) (free text }\end{array}$ \\
\hline 70. Adverse events not related to thrombolysis & $\begin{array}{l}\text { (select one option) } \\
\text { 1. Yes } \\
\text { 2. No } \\
\text { 9. Unknown/not documented }\end{array}$ \\
\hline $\begin{array}{l}\text { 71. Was it serious, if yes, type of serious adverse } \\
\text { event }\end{array}$ & $\begin{array}{l}\text { (select one option) } \\
\text { 1. Yes } \\
\text { 2. No } \\
\text { If yes, select types of serious adverse event (if selected, } \\
\text { code=1)? } \\
\text { Type of serious adverse event: } \\
\text { - Aspiration pneumonia } \\
\text { - Other chest infection } \\
\text { - Symptomatic haemorrhage } \\
\text { - Asymptomatic haemorrhage } \\
\text { - Decubitus ulcer } \\
\text { - UTI } \\
\text { - DVT } \\
\text { - Fall }\end{array}$ \\
\hline
\end{tabular}


- Coma

- Seizure

- Acute MI

- Shoulder complications

- Pulmonary Embolism

- Other

o (specify other) (free text box)

\section{Endovascular treatment}

72. Was other reperfusion (endovascular) treatment recommended?

(select one option)

1. Yes

2. No

9. Unknown/not documented

73. Was other reperfusion (endovascular) treatment provided?

(select one option)

1. Yes

2. No

9. Unknown/not documented

74. If other reperfusion (endovascular) treatment (Select those that apply. If selected, code $=1$ ) recommended but not provided, why was recommendation not followed?

- Significant pre-stroke disability (pre-stroke mRS $>1)$

- No evidence of proximal occlusion

- $\quad$ NIHSS $<6$

- Brain imaging not favourable/haemorrhage transformation (ASPECTS score $<6$ )

- Groin puncture could not be initiated within 6 hours of symptom onset

- Anatomical reason - unfavourable vascular anatomy that limits access to the occluded artery

- Patient/Family refusal

- MER performed at outside hospital

- Equipment-related delay

- No endovascular specialist available

- Delay in stroke diagnosis

- Vascular imaging not performed

- Advanced age

- Other o (specify other reason) (free text box)

75. Was patient transferred for other reperfusion

(select one option) (endovascular) treatment?

1. Yes

2. No

9. Unknown/not documented

If yes, record mode of transport used:

- Road Ambulance/Emergency Medical Service - Standard - Mobile Stroke Unit

- Air Ambulance/Emergency Medical Service - Plane - Helicopter

- Private transport/car service 
76. Hospital details patient was transferred to for other reperfusion (endovascular) treatment.

77. Date and time of patient transfer for reperfusion (endovascular) treatment?
- Hospital name (alphanumeric text box)

- State (free text box)

- Country (use AuSCR country codes)

- Date

- DDMMYYYY (only numeric text)

- Time: $24 \mathrm{hr}$ time

○ hh:mm (e.g., 13:53) (only numeric text)

○ Unknown/not documented

- Date

- DDMMYYYY (only numeric text)

- Time: $24 \mathrm{hr}$ time

○ hh:mm (e.g., 13:53) (only numeric text)

○ Unknown/not documented

- Date

- DDMMYYYY (only numeric text)

○ Unknown/not documented

- Score

○ $\quad \mathrm{NN}(0-42,99=$ unknown $)$ other reperfusion (endovascular) treatment

81. Time of groin puncture

- Time: $24 \mathrm{hr}$ time

○ hh:mm (e.g., 13:53) (only numeric text)

○ Unknown/not documented

- Time: $24 \mathrm{hr}$ time

○ hh:mm (e.g., 13:53) (only numeric text)

○ Unknown/not documented

\section{Types of complications of endovascular procedure}

84. Final thrombolysis in cerebral infarction (TICI) score
- Free text

(select one option)

0 . Grade 0

1. Grade 1

2a. Grade $2 \mathrm{a}$

$2 b$. Grade $2 b$

2c. Grade 2c

3. Grade 3

9. Unknown/not documented

\section{Neurosurgery treatment}

85. Was other neurosurgical treatment recommended? (select one option)

1. Yes

2. No

9. Unknown/not documented

(Select those that apply. If selected, code $=1$ )

- Significant pre-stroke disability (pre-stroke mRS $>1$ )

- No evidence of proximal occlusion

- $\quad$ NIHSS $<6$

- Brain imaging not favourable/haemorrhage transformation (ASPECTS score $<6$ ) 


\begin{tabular}{|c|c|}
\hline & 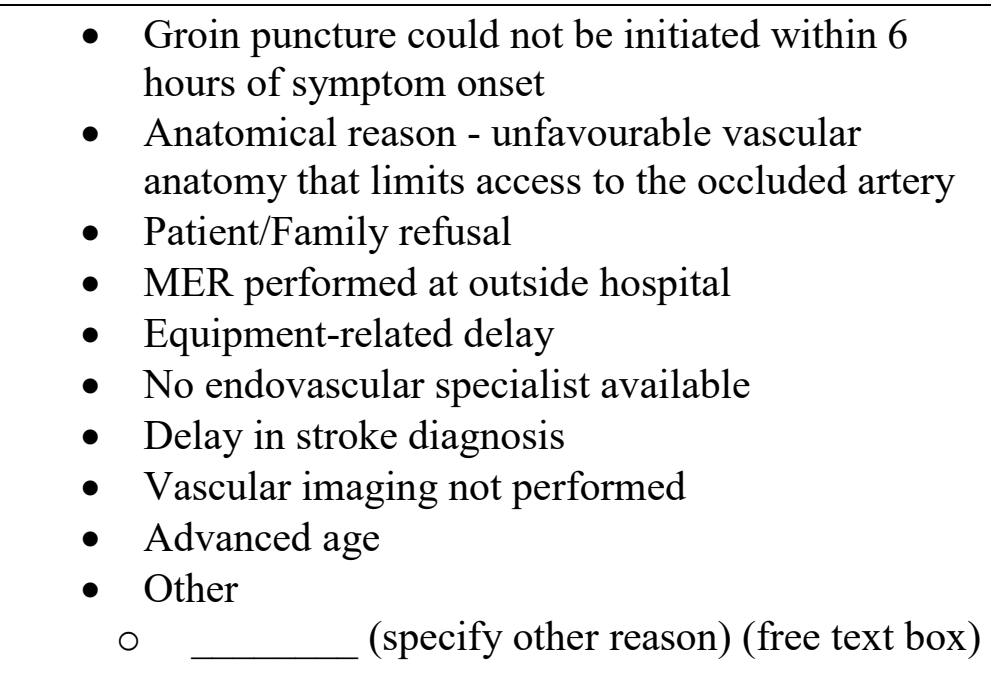 \\
\hline $\begin{array}{l}\text { 87. Was patient transferred for other neurosurgical } \\
\text { treatment? }\end{array}$ & $\begin{array}{l}\text { (select one option) } \\
\text { 1. Yes } \\
\text { 2. No } \\
\text { 9. Unknown/not documented }\end{array}$ \\
\hline 88. Type of neurosurgery performed? & $\begin{array}{l}\text { (select one option) } \\
0 \text {. None } \\
\text { 1. Hemicraniectomy } \\
\text { 2. Ventricular shunting } \\
\text { 3. Haematoma removal } \\
\text { 4. Other } \\
\qquad \quad \text { box) (specify other neurosurgery) (free text }\end{array}$ \\
\hline $\begin{array}{l}\text { 89. Hospital details patient was transferred to for } \\
\text { neurosurgery treatment. }\end{array}$ & $\begin{array}{ll}\text { - } & \text { Hospital name (alphanumeric text box) } \\
\text { - } & \text { State (free text box) } \\
\text { - } & \text { Country (use AuSCR country codes) }\end{array}$ \\
\hline $\begin{array}{l}\text { 90. Date and time of patient transfer for } \\
\text { neurosurgery? }\end{array}$ & $\begin{array}{l}\text { - Date } \\
\text { DDMMYYYY (only numeric text) } \\
\text { - Time: } 24 \mathrm{hr} \text { time } \\
\circ \text { hh:mm (e.g., 13:53) (only numeric text) } \\
\circ \text { Unknown/not documented }\end{array}$ \\
\hline $\begin{array}{l}\text { 91. Date and time of patient arrival to centre for } \\
\text { neurosurgery? }\end{array}$ & $\begin{array}{l}\text { - Date } \\
\text { DDMMYYYY (only numeric text) } \\
\text { - Time: } 24 \mathrm{hr} \text { time } \\
\circ \text { hh:mm (e.g., 13:53) (only numeric text) } \\
\circ \text { Unknown/not documented }\end{array}$ \\
\hline 92. Treatment date and time for neurosurgery. & $\begin{array}{l}\text { - Date } \\
\text { DDMMYYYY (only numeric text) } \\
\text { - Time: } 24 \mathrm{hr} \text { time } \\
\circ \text { hh:mm (e.g., 13:53) (only numeric text) } \\
\circ \text { Unknown/not documented }\end{array}$ \\
\hline
\end{tabular}




\section{Processes of care beyond the first 24 hours}

93. Symptomatic intracerebral haemorrhage reported.

1. Yes

2. No

9. Unknown/not documented

94. Asymptomatic intracerebral haemorrhage reported.

(select one option)

1. Yes

2. No

9. Unknown/not documented

95. Followup Computed Tomography scan at 24 hours.

(select one option)

1. Yes

2. No

9. Unknown/not documented

96. Was there haemorrhage within the infarct on follow-up imaging?

(select one option)

1. Yes

2. No

9. Unknown/not documented
97. Details of haemorrhage at 24 hours followup

98. Was the patient treated in a stroke unit at any time during their stay?

99. Was the patient referred to a tertiary centre / comprehensive stroke centre / teaching hospital / other?
- Free text

(select one option)

1. Yes

2. No

9. Unknown/not documented

(select one option)

1. Yes

2. No

9. Unknown/not documented

\section{Discharge information}

100. What is the discharge diagnosis ICD10 Classification Code? (select one option)

- $\quad \mathrm{I} 61.0$ - I61.6, I61.8, I61.9

- $\quad$ I62.9

- $\mathrm{I} 63.0$ - I63.6, I63.8, I63.9

- $\mathrm{I} 64.0$

- G45.9

- Other (OTH)

O field, upper case.)
101. Patient deceased during hospital care? If yes, what is the date of death, and cause? (select one option)

1. Yes

2. No

If yes, provide date:

- Date

- DDMMYYYY (only numeric text)

If yes, select cause of death (select one option)

1. Cerebral infarct (CI) 
2. Cerebral haemorrhage $(\mathrm{CH})$

3. Cerebral infarct and haemorrhage without specification (CIH)

4. Myocardial infarction (MI)

5. Pulmonary embolism (PE)

6. Pneumonia (PN)

7. Cardiac failure $(\mathrm{CF})$

8. Other vascular cause (OVC)

9. Other $(\mathrm{OTH})$

○ (specify other cause) (free text box)

102. Discharge date and time (from hospital)?

- Date

○ DDMMYYYY (only numeric text)

- Time: $24 \mathrm{hr}$ time

○ hh:mm (e.g., 13:53) (only numeric text)

○ Unknown/not documented

103. If transferred to another hospital, date and time of arrival at receiving hospital?

104. What is the discharge destination/mode?
- Date

- DDMMYYYY (only numeric text)

- Time: $24 \mathrm{hr}$ time

○ hh:mm (e.g., 13:53) (only numeric text)

○ Unknown/not documented

(select one option)

1. Discharge/transfer to (an)other acute hospital

2. Discharge/transfer to a residential aged care service unless this is the usual place of residence

5. Statistical discharge - type change

6. Left against medical advice/discharge at own risk

8. Died

9. Other

10. Usual residence (e.g., home) with supports

11. Usual residence (e.g., home) without supports

12. Inpatient rehabilitation

13. Transitional care services

If discharge/transfer to a residential aged care service unless this is the usual place of residence, select level of care (select one option)

1. Low level residential care (LLRC)

2. High level residential care (HLRC)

\section{Post-discharge and follow-up}

105. Time points of follow-up

106. Is patient deceased post hospital discharge, if so what is the date?
(Select those that apply. If selected, code $=1$ )

- 3 months

- 12 months

- Other

(select one option)

1. Yes

2. No

9. Unknown/not documented

If yes, provide date: 


\begin{tabular}{|c|c|}
\hline & $\begin{array}{l}- \text { Date } \\
\circ \quad \text { DDMMYYYY (only numeric text) }\end{array}$ \\
\hline 107. Where are you staying at present? & $\begin{array}{l}\text { 0. Missing } \\
\text { 1. High level Residential care } \\
\text { 2. Low level Residential care } \\
\text { 3. Home with supports } \\
\text { 4. Home without supports } \\
\text { 5. Hospital } \\
\text { 6. Rehabilitation (inpatient) } \\
\text { 7. Transitional care services } \\
\text { 8. Other (specify other) (free text box) }\end{array}$ \\
\hline 108. Do you live on your own? & $\begin{array}{l}\text { (select one option) } \\
\text { 1. Yes } \\
\text { 2. No } \\
\text { 9. Unknown/not documented }\end{array}$ \\
\hline $\begin{array}{l}\text { 109. Since you were in hospital for stroke, have you } \\
\text { had another stroke? Date of readmission. }\end{array}$ & $\begin{array}{l}\text { (select one option) } \\
\text { 1. Yes } \\
\text { 2. No } \\
\text { 9. Unknown/not documented } \\
\text { If yes, provide date: } \\
\quad \text { Date } \\
\quad \circ \quad \text { DDMMYYYY (only numeric text) }\end{array}$ \\
\hline $\begin{array}{l}\text { 110. Post stroke modified Rankin score (assessed by } \\
\text { self-report, telestroke network) }\end{array}$ & $\begin{array}{l}\text { Collected at day } 7-10 \text { or discharge if earlier than day } 7 \\
\text { and at } 90 \text { days (if resources available) } \\
\text { (select one option) } \\
\text { 0. No symptoms. } \\
\text { 1. No significant disability. Able to carry out all usual } \\
\text { activities, despite some symptoms. } \\
\text { 2. Slight disability. Able to look after own affairs without } \\
\text { assistance, but unable to carry out all previous } \\
\text { activities. } \\
\text { 3. Moderate disability. Requires some help, but able to } \\
\text { walk unassisted. } \\
\text { 4. Moderately severe disability. Unable to attend to own } \\
\text { bodily needs without assistance, and unable to walk } \\
\text { unassisted. } \\
\text { 5. Severe disability. Requires constant nursing care and } \\
\text { attention, bedridden, incontinent. } \\
\text { 6. Death }\end{array}$ \\
\hline
\end{tabular}




\section{Other information for database setup}

Recommended for data coding:

Yes $=1, \mathrm{No}=2$, Unknown $/$ Not documented $=9$

Dates $=$ DDMMYYYY

Times $=$ hh:mm or mm only

\section{DATA DICTIONARY Supplemental References}

Acute Stroke Telemedicine: Utility, Training and Evaluation, http://www.astutetelestroke.org.uk/

Australian National Stroke Data Dictionary, July 2018

Get with The Guidelines, Case Record Form, August 2018

METeOR, National Health Data Dictionary http://meteor.aihw.gov.au AuSDAT

VST Victorian Stroke Telemedicine (VST) Program: Data Dictionary, November 2014, Version 1.3

VST Neurologist Consultation Form, Data Dictionary Code Book, April 2019 